\title{
Screening Retroviral Packaging Cells for Highly Efficient Virus Production by Using a Combined Selection Procedure
}

\author{
M. WIRTH, R. GRANNEMANN, D. KLEHR, AND H. HAUSER* \\ GBF-Gesellschaft für Biotechnologische Forschung mbH, Genetics of Eukaryotes, \\ D-38124 Braunschweig, Germany
}

Received 24 June 1991/Accepted 28 September 1993

\begin{abstract}
To facilitate the screening for clones of transfected packaging cells producing a high yield of recombinant retrovirus, we present a fast and simple method for the isolation of overexpressing cells. By this method the efficiency of virus production can generally be enhanced 10- to 100-fold by application of high selection pressure. Cell lines which exhibit titers of up to $10^{8} \mathrm{CFU} / \mathrm{ml}$ were obtained.
\end{abstract}

Gene transfer via retroviral infection is an efficient method for the introduction of foreign genes into a broad range of cell lines. Viral stocks are obtained by transfection of packaging cell lines $(3,4,8,9,11-13)$. Stably transfected packaging cells vary widely with respect to virus formation. Therefore, timeconsuming subcloning and screening steps are necessary to obtain high-titer cell clones.

We demonstrate a simple and rapid procedure to screen for viral packaging cells producing elevated levels of virus. The procedure is based on the selection of overexpressing cells from a population of cells expressing the transferred retroviral vector. Cells expressing elevated levels of cotransferred DNA encoding a selective marker(s) and the gene of interest (retroviral vector) can survive the application of high selection pressure. In order to avoid upon increased drug concentrations the appearance of resistant clones which are not due to the expression of selective markers, a simultaneous screening for expression of a second selective gene is applied. The concerted application of high selection pressure onto one resistance gene (high-level selective marker) and fundamental selection for the second resistance gene (basal-level selective marker) give rise to a relatively low number of transfectants. Cell clones derived from such a selection express 5- to 20-fold more of a cotransferred gene than do cell clones from a usual selection procedure. This is due to elevated copy numbers of the transferred genes as well as integration into transcriptionally active loci. Previously, we have applied this principle to screen for cells overexpressing secreted proteins from transfected genes (19).

The application of the combined selection procedure to the screening of transfected packaging cells leads to stable cell clones exhibiting high-level production of recombinant retrovirus. To demonstrate this, we determined virus production from pM5ATIII in $\Psi 2$ cells after cotransfer with pSV2pac and combined selection. pSV2pac contains the puromycin resistance gene (18) (Fig. 1A). pM5ATIII contains the neomycin resistance gene from Tn5 and the cDNA gene of human antithrombin III (20). Three flasks with $3 \times 10^{5} \Psi 2$ cells were cotransfected with $5 \mu \mathrm{g}$ of the retroviral construct and $0.5 \mu \mathrm{g}$ each of pSV2pac and carrier DNA. Two days after transfection, selection was applied by addition of $1 \mathrm{mg}$ of G418 per ml alone or together with different concentrations of puromycin.

\footnotetext{
* Corresponding author. Mailing address: Genetics of Eukaryotes, GBF-Gesellschaft für Biotechnologische Forschung $\mathrm{mbH}$, Mascheroder Weg 1, D-38124 Braunschweig, Germany. Phone: (531) 6181-250. Fax: (531) 6181-262. Electronic mail address: HHA@VENUS.GBF-Braunschweig.D400.DE.
}

Cells $\left(3 \times 10^{5}\right)$ of pools of resistant cell clones from each selection were seeded into T25 flasks. Fresh culture medium ( 3 $\mathrm{ml}$ ) was added 1 day later, and cells were kept for a 24-h production period, after which a density of $70 \%$ confluency was reached. After removal of the supernatant, cells were counted. NIH 3 T3 cells $\left(1.5 \times 10^{3} / \mathrm{cm}^{2}\right)$ were infected with filtered (0.4- $\mu \mathrm{m}$ pore size), diluted supernatants supplemented with $8 \mu \mathrm{g}$ of Polybrene per ml. Medium was changed 1 day later, and then selective medium was added 2 days after infection (1 mg of G418 per ml). The data in Fig. 1B show that simultaneous selection versus single selection indeed results in 15 -fold-increased virus production from a diminished cell population.

Theoretically, the strength of virus production from cells resistant to the combined selection should be due to an increased steady-state level of the specific mRNA. Poly $(\mathrm{A})^{+}$ RNA from transfected packaging cells surviving different selection pressures was analyzed with Northern (RNA) blots (Fig. 1C). Steady-state levels of the unspliced RNA parallel virus production (Fig. 1) and the amount of secreted antithrombin III (data not shown) from transfected packaging cells.

Replacement of the neomycin resistance gene by the puromycin resistance gene in retroviral vectors is advantageous for two reasons. First, the neomycin gene sequence silences adjacent promoters (1). Second, in this type of vector the production of genomic viral RNA should be directly coupled to the expression of the drug resistance gene. Therefore, those transfectants exhibiting elevated resistance to high concentrations of the corresponding selective drug should release higher levels of recombinant retrovirus. Experimental results with this type of vector are shown in Fig. 2. In pM6pac the puromycin resistance gene is controlled by the long terminal repeat (LTR) (Fig. 2A). A 30-fold increase (relative to results obtained with single selection) of virus production was determined when a combined selection for a cotransfected neomycin resistance gene was used. Single selection with increasing puromycin concentrations does not give rise to a high virus titer (Fig. 2B). $\mathrm{Up}$ to a 100 -fold increase of virus production can be obtained after insertion of a reporter gene (cat) transcribed from the internal simian virus 40 early promoter (Fig. 2C and D). A similar type of retrovirus vector in which the puromycin resistance gene is under the control of an internal promoter was constructed by Morgenstern and Land (13) (Fig. 2E). Packaging efficiency is increased because of the presence of a part of the gag region in the vector. Figure $2 \mathrm{~F}$ shows that the 


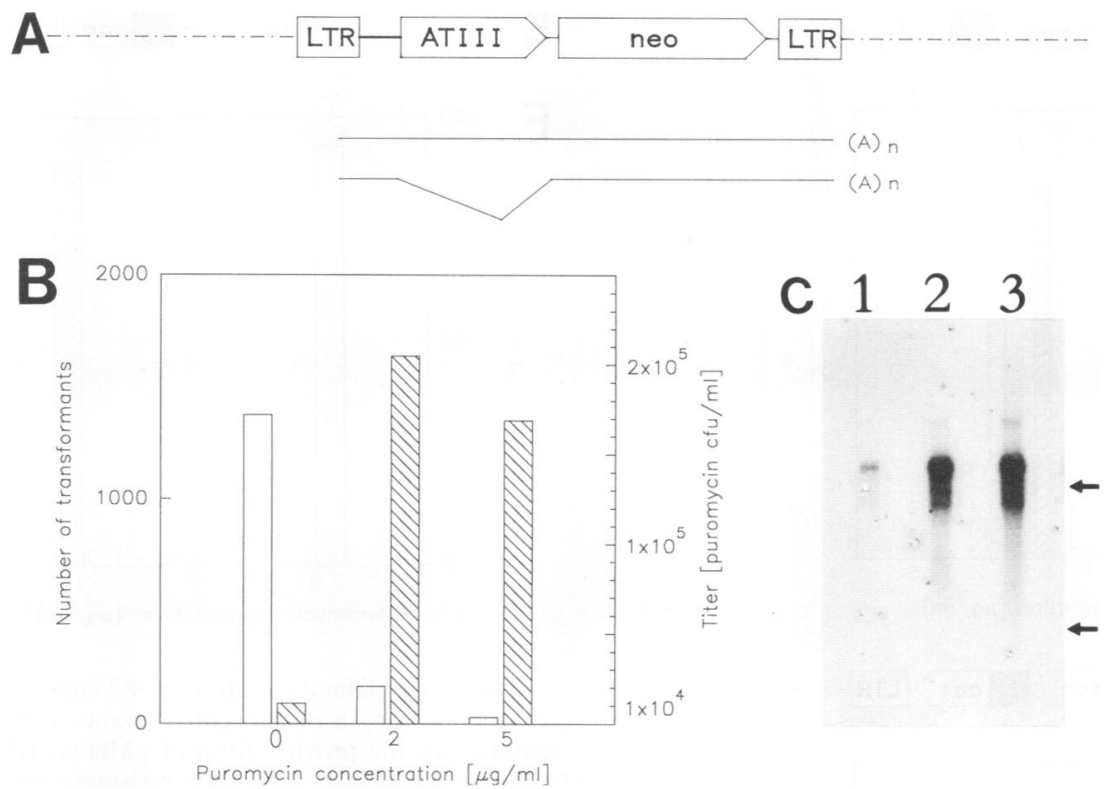

FIG. 1. Combined selection of $\Psi 2$ cells transfected with pM5ATIII. (A) Schematic representation of the proviral form of the retrovirus vector pM5ATIII. The 1.4-kb human antithrombin III cDNA was inserted into the single BamHI restriction site of pM5neo (6). Symbols and abbreviations: LTR, LTR of the myeloproliferative sarcoma virus; neo, neomycin resistance gene from Tn5; ATIII, antithrombin III; broken line, host genomic DNA; line between $5^{\prime}$ LTR and first gene, $\Psi$ packaging signal. The lines below represent the expected full-length and spliced mRNAs (middle and bottom, respectively). (B) Virus production and transformation efficiency upon combined selection of $\Psi 2$ cells. $\Psi 2$ cells were cotransfected with pM5ATIII and pSV2pac. Selection was performed with G418 alone or with G418 and different concentrations of puromycin. Viral titers were determined in a G418 CFU test on NIH 3T3 cells as described in the text. The results from a typical experiment are shown. Symbols: open bars, number of transfectants; hatched bars, viral titer. (C) Northern blot analysis of poly(A) ${ }^{+}$RNA from transfected $\Psi 2$ packaging cells. Poly $(\mathrm{A})^{+}$RNA $(5 \mu \mathrm{g})$ was electrophoresed, blotted, and hybridized to ${ }^{32}$ P-labeled antithrombin III cDNA. Rehybridization of the blot was performed with ${ }^{32} \mathrm{P}$-labeled rat $\beta$-actin DNA to confirm equal amounts of RNA (data not shown). Arrows: 28S (upper) and 18S (lower) RNA from $\Psi 2$ cells. RNA was from cells derived from selection with $1 \mathrm{mg}$ of $\mathrm{G} 418$ (weight of powder) per $\mathrm{ml}$ (lane 1 ), combined selection with $1 \mathrm{mg}$ of G418 per $\mathrm{ml}$ and $2 \mu \mathrm{g}$ of puromycin per $\mathrm{ml}$ (lane 2), or $1 \mathrm{mg}$ of $\mathrm{G} 418$ per $\mathrm{ml}$ and $5 \mu \mathrm{g}$ of puromycin per $\mathrm{ml}$ (lane 3 ).

application of the combined selection results in cells with viral titers of up to $10^{8} \mathrm{CFU} / \mathrm{ml}$.

In several studies replication-competent retroviruses from transfected $\Psi 2$ cells were detected (e.g., see references 7, 10, and 15). The high virus titer achieved by the combined selection protocol could be due to the creation of such replication-competent retroviruses. We have investigated this possibility by testing supernatants from stably transfected $\Psi 2$ cells after single and combined selection using the XC assay (14) and a marker rescue assay (3). NIH 3T3 cells stably transfected with pMLVDHFR*5 (17) were used as a positive control for both assays. pMLVDHFR $* 5$ carries the murine leukemia virus provirus and a dihydrofolate reductase gene within the $3^{\prime}$ LTR. Supernatants from these cells induce $3 \times$ $10^{6}$ focus-forming units $/ \mathrm{ml}$ in the $\mathrm{XC}$ assay and transfer the HisD phenotype in the marker rescue assay (Table 1). Supernatants from $\Psi 2$ cells transfected with the retroviral vectors pM6pac and pBabepuro as shown in Fig. 2A and $E$ were subjected to both assays. In the $\mathrm{XC}$ assay no replicationcompetent viruses could be detected. However, the HisD marker was mobilized with supernatants from $\Psi 2$ helper cells producing high titers of the recombinant pM6pac retrovirus (Table 1). On the other hand, high-virus-titer supernatants from helper cells derived by combined selection with pBabepuro do not give rise to a marker rescue. Reverse transcriptase (RT) activity in the supernatants from infected 116 cells (mobilizing cells) was determined and found to correlate with the mobilization of the infected viruses. The data indicate that the creation of replication-competent viruses in $\Psi 2$ helper cells is dependent on the retroviral construct. The high-titer virus batch achieved with the combined selection procedure for pBabepuro is free of such viruses. Therefore, the combined selection procedure per se selects only for highly virus-producing cells. The procedure does not induce the creation of replication-competent viruses, nor is the high titer that is achieved due to such contaminating viruses.

According to our experience with the combined selection protocol for many (packaging) cell lines, we presume that the procedure yields a mixture of subclones exhibiting high virus titer irrespective of retroviral vector or packaging cell line, provided that the packaging functions are sufficiently expressed. To achieve maximum results, we suggest determining the optimal concentration of selective drug for each given cell line and vector.

The lack of simple procedures for the screening of retroviral packaging cell clones stimulated the development of alternative methods to overcome the elaborative subcloning and testing of cells. Strair and coworkers showed that high-titer virus producers can be isolated from a population of $\Psi 2$ transfectants by fluorescence-activated cell sorting based on the presence of cell surface antigens from the recombinant retroviruses as coexpression markers (16). By the recently developed ping-pong amplification method, a 2 - to 10-fold relative increase in titer was reported with absolute values of up to at least $10^{8} \mathrm{CFU} / \mathrm{ml}$ (the initially reported $10^{10} \mathrm{CFU} / \mathrm{ml}$ could not be confirmed). The method implies alternating infection by the recombinant virus derived from cocultivation of two packaging cell lines, one expressing ecotropic and the 

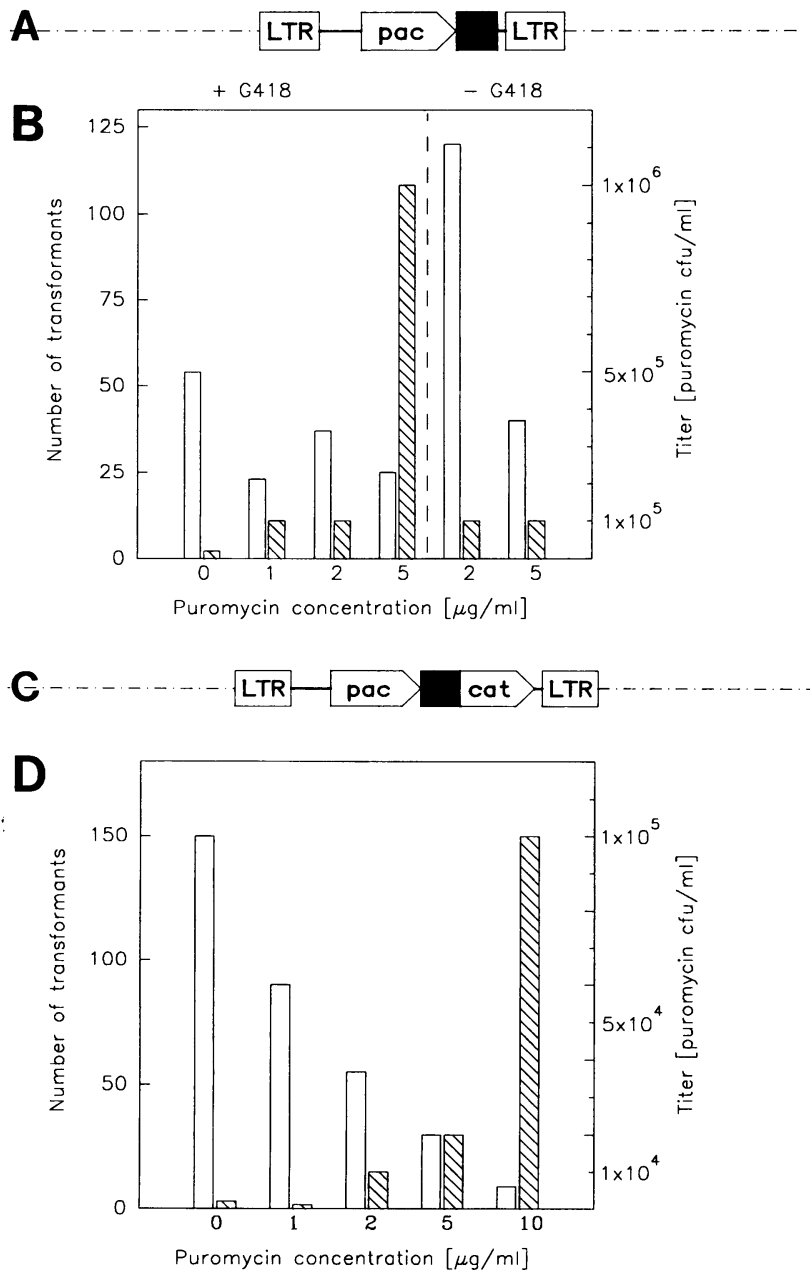

other expressing amphotropic env genes $(2,5,7)$. However, extensive virus recombinations which decrease the application of the method for a number of purposes, e.g., human gene therapy, have been observed in the use of several packaging

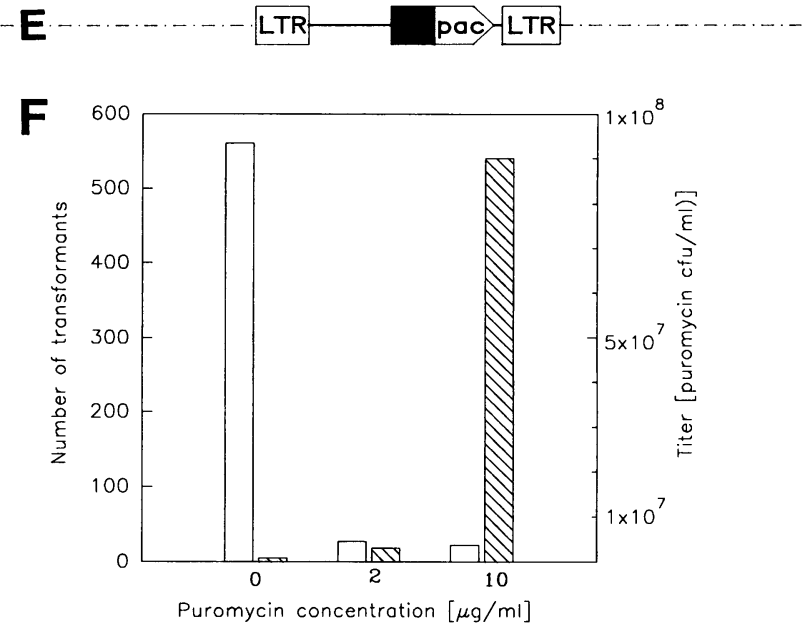

FIG. 2. Combined selection of $\Psi 2$ cells transfected with retroviral vectors encoding a puromycin resistance gene. (A) Schematic representation of the proviral form of pM6pac. pM6pac is a derivative of pM5neo in which the neomycin resistance gene and all gag sequences are replaced by a puromycin resistance gene (pac). The open boxes depict the myeloproliferative sarcoma virus LTR and the pac gene as indicated. The pac gene is transcriptionally controlled by the LTRs. The black box represents the simian virus 40 early promoter, and the broken line shows the host genomic DNA. (B, D, and F) Virus production and transfection efficiency upon combined selection of $\Psi 2$ cells. The results were obtained as described in the legend to Fig. 1B, except that pSV2pac was replaced by a neomycin expression plasmid and the virus titer was determined in a puromycin CFU test on NIH $3 T 3$ cells. Results from typical experiments are shown. (C) Schematic representation of pM5pacat as a provirus. Symbols are as described for panel A. The cat gene was inserted into the polylinker of pM5pac downstream of the simian virus 40 early promoter. (E) Schematic representation of pBabepuro as a provirus. For a detailed description of the vector, see the report of Morgenstern and Land (13). LTR, murine leukemia virus LTR; black box, simian virus 40 early enhancerpromoter; extended line between LTR and the black box in pBabepuro, packaging-promoting gag sequence.

cell line-vector combinations. We think, however, that the presented screening procedure for packaging cells is a simple, fast, and inexpensive alternative to obtain high-titer-virus producers.

TABLE 1. Determination of replication-competent retroviruses from transfected $\Psi 2$ cells

\begin{tabular}{|c|c|c|c|c|c|c|}
\hline \multirow[b]{2}{*}{ Vector } & \multicolumn{2}{|c|}{ Selection $^{a}$ with: } & \multirow{2}{*}{$\begin{array}{l}\text { Virus titer } \\
\text { (CFU/ml) }\end{array}$} & \multirow{2}{*}{$\begin{array}{l}\text { XC titer } \\
\text { (PFU/ml) }\end{array}$} & \multirow{2}{*}{$\begin{array}{l}\text { Marker rescue }{ }^{d} \\
\text { (mobility assay) }\end{array}$} & \multirow{2}{*}{$\begin{array}{c}\mathrm{RT} \\
\text { activitye }^{e^{2}}\end{array}$} \\
\hline & $\begin{array}{l}\mathrm{G} 418 \\
(\mathrm{mg} / \mathrm{ml})\end{array}$ & $\begin{array}{l}\text { Puromycin } \\
(\mu \mathrm{g} / \mathrm{ml})\end{array}$ & & & & \\
\hline \multirow[t]{2}{*}{ pM6pac } & 1 & 0 & $2 \times 10^{4}$ & $<2$ & - & ND \\
\hline & 1 & 5 & $1 \times 10^{6}$ & $<2$ & + & + \\
\hline \multirow[t]{2}{*}{ pBabepuro } & 1 & 0 & $9 \times 10^{5}$ & $<2$ & - & ND \\
\hline & 1 & 10 & $9 \times 10^{7}$ & $<2$ & - & - \\
\hline pMLVDHFR*5 & 0 & 0 & $1 \times 10^{5 *}$ & $3 \times 10^{6}$ & + & + \\
\hline
\end{tabular}

${ }^{a}$ Virus-producing cells were obtained by transfection of $\Psi 2$ cells with the indicated vectors and subsequent selection with the indicated selective drugs as detailed in the figure legends (for pM6pac and pBabepuro). For pMLVDHFR*5, $5 \mu \mathrm{g}$ of methotrexate per ml was used for selection.

"Virus production was measured by titration of the cell supernatants from vector transfectants on NIH 3 T3 cells as puromycin- and methotrexate $\left({ }^{*}\right)$-resistant cell clones.

${ }^{c}$ Formation of replication-competent retroviruses was measured as described by Rowe et al. (14) 2 weeks after virus titration.

"Supernatants of stably transfected $\Psi 2$ cell lines were taken for infection of 116 cells (3). Five days after infection the supernatants from 116 cells were tested for their ability to transfer the HisD phenotype to NIH 3 T3 cells. Resistant NIH 3 T3 clones were selected in 10 mM histidinol. + , selection of resistant cell clones (between 20 and 200$) ;-$, no clones detectable.

${ }^{c} \mathrm{RT}$ activity from 116 cells 5 days after treatment with respective $\Psi 2$ supernatants. + , RT activity; - , no RT activity; ND, not done. 
We thank H. Land for providing pBabepuro, C. Stocking for pM5neo, H. Stuhlmann for pMLVDHFR*5, I. Dortmund for preparing the manuscript, S. Emery for critical reading of the manuscript, and L. Schumacher for excellent technical assistance.

\section{REFERENCES}

1. Artelt, P., R. Grannemann, C. Stocking, J. Friel, J. Bartsch, and H. Hauser. 1991. The prokaryotic neomycin-resistance-encoding gene acts as a transcriptional silencer in eukaryotic cells. Gene 99:249-254.

2. Bodine, P. M., K. T. McDonagh, S. J. Brandt, P. A. Ney, B. Agricola, E. Byrne, and A. W. Nienhuis. 1990. Development of a high-titer retrovirus producer cell line capable of gene transfer into rhesus monkey hematopoietic stem cells. Proc. Natl. Acad. Sci. USA 87:3738-3742.

3. Danos, O., and R. C. Mulligan. 1988. Safe and efficient generation of recombinant retroviruses with amphotropic and ecotropic host ranges. Proc. Natl. Acad. Sci. USA 85:6460-6464.

4. Dougherty, J. P., R. Wisniewski, S. Yang, B. W. Rhode, and H. M. Temin. 1989. New retrovirus helper cells with almost no nucleotide sequence homology to retrovirus vectors. J. Virol. 63:3209-3212.

5. Kozak, S. L., and D. Kabat. 1990. Ping-pong amplification of a retroviral vector achieves high-level gene expression: human growth hormone production. J. Virol. 64:3500-3508.

6. Laker, C., C. Stocking, U. Bergholz, N. Hess, S. F. De Lamarter, and W. Ostertag. 1987. Autocrine stimulation after transfer of the granulocyte/macrophage colony-stimulating factor gene and autonomous growth are distinct but independent steps in the oncogenic pathway. Proc. Natl. Acad. Sci. USA 84:8458-8462.

7. Lynch, C. M., and A. D. Miller. 1991. Production of high-titer helper virus-free retroviral vectors by cocultivation of packaging cells with different host ranges. J. Virol. 65:3887-3890.

8. Mann, R., R. Mulligan, and D. Baltimore. 1983. Construction of a retrovirus packaging mutant and its use to produce helper-free defective retrovirus. Cell 33:153-159.

9. Markowitz, D., S. Goff, and A. Bank. 1988. A safe packaging line for gene transfer: separating viral genes on two different plasmids.
J. Virol. 62:1120-1124.

10. Miller, A. D., and C. Buttimore. 1986. Redesign of retrovirus packaging cell lines to avoid recombination leading to helper virus production. Mol. Cell. Biol. 6:2895-2902.

11. Miller, A. D., M.-F. Law, and I. Verma. 1985. Generation of helper-free amphotropic retroviruses that transduce a dominantacting, methotrexate-resistant dihydrofolate reductase gene. Mol. Cell. Biol. 5:431-437.

12. Miller, A. D., and E. J. Rosman. 1989. Improved retroviral vectors for gene transfer and expression. BioTechniques 7:980-990.

13. Morgenstern, J. P., and H. Land. 1990. Advanced mammalian gene transfer: high titer retroviral vectors with multiple drug selection markers and a complementary helper-free packaging cell line. Nucleic Acids Res. 18:3587-3596.

14. Rowe, W. P., W. E. Pugh, and J. W. Hartley. 1970. Plaque assay techniques for murine leukemia viruses. Virology 42:1136-1139.

15. Scarpa, M., D. Cournoyer, D. M. Muzny, K. A. Moore, S. W. Belmont, and C. T. Caskey. 1991. Characterization of recombinant helper retroviruses from Moloney-based vectors in ecotropic and amphotropic packaging cell lines. Virology 180:849-852.

16. Strair, R. K., M. J. Towle, and B. R. Smith. 1988. Recombinant retroviruses encoding cell surface antigens as selectable markers. J. Virol. 62:4756-4759.

17. Stuhlmann, H., R. Jaenisch, and R. C. Mulligan. 1989. Construction and properties of replication-competent murine retroviral vectors encoding methotrexate resistance. Mol. Cell. Biol. 9:100108.

18. Vara, J. A., A. Portela, J. Ortin, and A. Jimenez. 1986. Expression in mammalian cells of a gene from Streptomyces alboniger conferring puromycin resistance. Nucleic Acids Res. 14:4617-4624.

19. Wirth, M., J. Bode, G. Zettlmeissl, and H. Hauser. 1988. Isolation of overproducing recombinant mammalian cell lines by a fast and simple selection procedure. Gene 73:419-426.

20. Zettlmeissl, G., H. Ragg, and H. E. Karges. 1987. Expression of biologically active human antithrombin III in Chinese hamster ovary cells. Bio/Technology 5:720-725. 


\section{HELMHOLTZ ZENTRUM FÜR INFEKTIONSFORSCHUNG}

This is a copy of the free text from BioMed Centrals Repository (PMC)

PMCID: (236323 )

http://www.ncbi.nIm.nih.gov/pme/articles/PMC236323/

published in

Wirth, M., Grannemann, R., Klehr, D., Hauser, H. Screening retroviral packaging cells for highly efficient virus production by using a combined selection procedure

(1994) Journal of Virology, 68 (1), pp. 566-569. 